can be tried in patients with AS. The obstetric and perinatal outcomes in women with AS were also comparable to normal pregnant women.

Disclosure of Interest: None declared

DOI: 10.1136/annrheumdis-2017-eular.2511

\section{SAT0399 HEADACHE AS A CLINICAL COMPLAINT AT INITIAL PRESENTATION AND DURING THE DISEASE COURSE IN PATIENTS WITH SPONDYLOARTHRITIS INDICATES CONCOMITANT / SECONDARY FIBROMYALGIA}

E. Roussou, M. Karela, A. Georgiou. Rheumatology, Barking, Havering and Redbridge University Hospitals NHS Trust, London, United Kingdom

Objectives: To evaluate the symptom of headache as being able to clinically distinguish associated secondary fibromyalgia in patients with spondyloarthropathies (SpA). To compare the incidence of MSK complaints (related to SpA) in patients with headache to those that did not. To assess headache during the SpA disease course.

Methods: Registry data from 776 patients seen in clinic with SpA were analysed with reference to headache as symptom at presentation. The data of those patients presented with headache were compared with data of those patients who did not report headache with regards to demographics and disease characteristics. In addition, other MSK complaints, fatigue and pain during disease course were also analysed.

Results: From a total of 776 patients ( $m$ : $f=265: 508)$ age $48.3(S D+14.1$ ), 13 were excluded as no answer was recorded. $117 / 763$ patients (15.08\%) representing 28 males and 89 females $(23.9 \%$ vs $76.1 \%$ ratio $1: 3.1)$ reported headache at disease onset.

During the disease course, 13 patients out of the initial 117 did not record an answer to the question and were excluded. From remaining 104 patients, 95 patients $(91.3 \%)$ continued to describe headache as a symptom.

From those not reporting headache as initial symptom, $(n=659) 148$ did not record an answer and were excluded. From the remaining 511 patients, 194 (37.9\%) reported headache during the disease course.

On the data obtained from these 2 sub-groups, comparison took place using paired sample t-test.

Table shows demographics and disease characteristics as well as differences between the $2 \mathrm{SpA}$ sub-groups. Those presenting with headache describe worse disease, more fatigue and a greater percentage describe pain at pressure points and MSK system.

\begin{tabular}{|c|c|c|c|c|}
\hline & $\begin{array}{c}\text { Headache at } \\
\text { presentation } \\
(n=117)\end{array}$ & $\begin{array}{l}\text { No headache at } \\
\text { presentation } \\
(n=656)\end{array}$ & $\begin{array}{l}\text { Statistical } \\
\text { significance } \\
\text { (p) }\end{array}$ & $\mathrm{Cl}$ \\
\hline Age (mean $\pm S D$ ) & $47.7(13.16)$ & $48.3(14.3)$ & 0.1 & -5.757 to 0.912 \\
\hline Gender (M:F) ratio & $28: 89(1: 3.1)$ & $219: 419(1: 1.9)$ & 0.3 & -0.025 to 0.077 \\
\hline Disease duration $(\mathrm{y})$ & & & & \\
\hline$($ mean $\pm S D)$ & $11.4(12.1)$ & $10.9(10.8)$ & 0.4 & -1.905 to 4.470 \\
\hline $\begin{array}{l}\text { Delay in diagnosis }(y) \\
(\text { mean }+S D)\end{array}$ & $6.43(8.9)$ & $6.3(8.1)$ & 07 & -3.151 to 2.151 \\
\hline $\mathrm{ESR}($ mean $\pm \mathrm{SD}) \mathrm{mmHg}$ & $15.5(14.8)$ & $18.2(18)$ & 0.07 & -11.064 to 0.582 \\
\hline CRP (mean \pm SD) mg/dL & $10.4(36)$ & $8.2(9.8)$ & 0.4 & -6.106 to 12.536 \\
\hline BASDAI score (mean \pm SD) & $7.31(3.7)$ & $6.06(2.08)$ & $<0.005$ & 0.783 to 2.624 \\
\hline BASFI score (mean \pm SD) & $5.6(2.7)$ & $5.04(2.7)$ & 0.09 & -0.143 to 1.626 \\
\hline Buttock pain (\%) & 31.6 & 12.8 & 0.001 & 0.083 to 0.293 \\
\hline Back pain (\%) & 82.9 & 58.8 & $<0.005$ & 0.125 to 0.337 \\
\hline Neck pain (\%) & 72.6 & 24.4 & $<0.005$ & 0.340 to 0.583 \\
\hline Knee pain (\%) & 63.2 & 30.6 & $<0.005$ & 0.284 to 0.520 \\
\hline Shoulder (\%) & 70.9 & 23 & $<0.005$ & 0.312 to 0.559 \\
\hline Foot $(\%)$ & 57.2 & 22 & $<0.005$ & 0.279 to 0.524 \\
\hline Hip (\%) & 55.5 & 19.9 & $<0.005$ & 0.217 to 0.467 \\
\hline Eye $(\%)$ & 23 & 4.3 & $<0.005$ & 0.102 to 0.274 \\
\hline Fatigue & $77 / 116$ (66.4\%) & $340 / 608$ (55.9\%) & 0.018 & 0.029 to 0.299 \\
\hline Pain with pressure & $71 / 117(61.2 \%)$ & $257 / 807$ (42.4\%) & 0.000 & 0.122 to 0.378 \\
\hline Headache as co-morbidity & 95 (109) $87.2 \%$ & $195 / 509$ (38.3\%) & 0.000 & 0.808 to 0.935 \\
\hline
\end{tabular}

Conclusions: Headache can clinically represent secondary FM among SpA patients. A proportion of patients (representing 15\%) report headache at presentation. The majority of those patients (>90\%) continue to describe headache during the disease course. From those patients who did not have headache at presentation, $38 \%$ report headache during the disease course. Patients describing headache at presentation have more MSK complaints at presentation. Disclosure of Interest: None declared

DOI: 10.1136/annrheumdis-2017-eular.5354

\section{SAT0400 IS WHIPLASH INJURY A TRIGGERING OR EXACERBATING FACTOR FOR AXIAL SPONDYLOARTHRITIS?}

F. Urano, S. Ono, R. Hara, M. Yasumura, T. Muramatsu, S. Suzuki. Arthritis and Lupus Center, J a Nagano Koseiren Shinonoi General Hospital, Nagano City, Japan

Background: Axial spondyloarthritis $(\mathrm{AxSpA})$ can be triggered by infection and environmental factors, and some cases involve trauma. Whiplash injury in a traffic accident may lead to exacerbation of symptoms of AxSpA.
Objectives: The aims of this study are to survey the prevalence of trauma before or after onset of $\mathrm{AxSpA}$ and to examine the prevalences of neck trauma and other trauma in patients with a history of AxSpA.

Methods: The patients completed a questionnaire, and clinical presentation, inflammatory markers (ESR, CRP), radiographs, MRI of sacroiliac joints, Bath ankylosing spondylitis disease activity index (BASDAI), Bath ankylosing spondylitis functional index (BASFI), and Bath ankylosing spondylitis metrology index (BASMI) were assessed. Onset of symptoms was evaluated using European criteria for spondyloarthritis and patients were asked about mechanical stress (spinal trauma, extremity trauma, and internal organ injury). Patients with rheumatoid arthritis (RA) were included as controls and underwent the same evaluation. Patients with neck trauma were divided into four groups based on a short ( $<3$ years) (group A) or long ( $\geq 3$ years) (group $B$ ) period between disappearance of trauma symptoms and onset of inflammatory back pain (IBP); continuous IBP after trauma (group C); and a gradual change from minor symptoms to severe IBP after trauma (group D). Results: The subjects were 124 patients with AxSpA and 102 with RA. Trauma occurred at a significantly higher rate in patients with AxSpA than in those with RA (66 $(53.2 \%)$ vs. $12(11.8 \%), p<0.0001)$. Neck trauma was also significantly more frequent in patients with AxSpA (63 (53.2\%) vs. 9 (8.8\%), $\mathrm{P}<0.0001)$ (Table 1). There were no significant differences in clinical background between patients with $\mathrm{AxSpA}$ with and without trauma (Table 2). Regarding the period from neck trauma to onset of IBP in patients with AxSpA, there were $4(6.3 \%), 22(34.9 \%)$, $14(22.2 \%)$, and $23(36.5 \%)$ cases in groups $A, B, C$ and $D$, respectively.

Table 1. Prevalence of items related to mechanical stress in patients with axial spondyloarthritis (AxSpA) and rheumatoid arthritis (RA)

\begin{tabular}{|l|c|c|c|}
\hline Item & $\begin{array}{c}\text { AxSpA } \\
\mathrm{n}(\%)(95 \% \mathrm{Cl})\end{array}$ & $\begin{array}{c}\mathrm{RA} \\
\mathrm{n}(\%)(95 \% \mathrm{Cl})\end{array}$ & $\begin{array}{c}\mathrm{P} \\
\text { value }\end{array}$ \\
\hline Cases (male/female) & $124(46 / 78)$ & $102(15 / 87)$ & \\
\hline Mean age (yrs) & $51.8 \pm 12.9^{*}(49.5-54.1)$ & $66.0 \pm 11.7^{*}(63.7-68.2)$ & $<0.0001$ \\
\hline Mean duration of illness (yrs) & $25.8 \pm 14.4^{*}(23.3-28.3)$ & $23.4 \pm 10.5^{*}(21.3-25.6)$ & 0.1294 \\
\hline Trauma to date & $66(53.2 \%)(44.4-62.0)$ & $12(11.8 \%)(5.5-18.0)$ & $<0.0001$ \\
\hline Neck trauma to date & $63(50.8 \%)(41.2-58.8)$ & $9(8.8 \%)(3.3-14.3)$ & $<0.0001$ \\
\hline Neck trauma before onset & $25^{* *}(20.2 \%)(13.1-27.2)$ & $9(8.8 \%)(3.3-14.3)$ & 0.1046 \\
\hline Lumbar trauma & $2(1.6 \%)(-0.6-3.8)$ & $1(1 \%)(-0.1-3.0)$ & 0.9244 \\
\hline Operation before onset & $33(26.6 \%)(18.8-34.4)$ & $16(15.7 \%)(8.6-22.7)$ & 0.1048 \\
\hline Fracture before onset & $9(7.3 \%)(2.7-11.8)$ & $7(6.9 \%)(2.0-11.8)$ & 0.9001 \\
\hline
\end{tabular}

n: Number of patients, $\mathrm{Cl}$ : confidence interval, * standard deviation, ${ }^{* *}$ groups $\mathrm{A}$ and $\mathrm{B}$

Table 2. Clinical features in patients with AxSpA and without trauma
\begin{tabular}{|l|c|c|c|}
\hline & $\begin{array}{c}\text { AxSpA with trauma } \\
\text { average } \pm \mathrm{SD}(95 \% \mathrm{Cl})\end{array}$ & $\begin{array}{c}\text { AxSpA without trauma } \\
\text { average } \pm \mathrm{SD}(95 \% \mathrm{Cl})\end{array}$ & $\begin{array}{c}\text { Statistical } \\
\text { significance }\end{array}$ \\
\hline $\mathrm{ESR}(\mathrm{mmHg} / \mathrm{h})$ & $10.48 \pm 9.39(8.21-12.75)$ & $12.84 \pm 15.32(8.90-12.78)$ & $\mathrm{ns}$ \\
\hline $\mathrm{CRP}(\mathrm{mg} / \mathrm{dl})$ & $0.23 \pm 0.42(0.13-0.33)$ & $0.35 \pm 0.78(0.15-0.55)$ & $\mathrm{ns}$ \\
\hline BASDAl & $2.66 \pm 1.24(2.36-2.96)$ & $2.40 \pm 1.23(2.08-2.72)$ & $\mathrm{ns}$ \\
\hline BASFI & $2.95 \pm 2.46(2.36-3.54)$ & $2.36 \pm 2.70(1.67-3.05)$ & $\mathrm{ns}$ \\
\hline BASMI & $2.62 \pm 1.58(2.24-3.00)$ & $2.48 \pm 1.69(2.05-2.91)$ & $\mathrm{ns}$ \\
\hline
\end{tabular}

$\mathrm{SD}$ : standard deviation, $\mathrm{Cl}$ : confidence interval, $\mathrm{ns}$ : not significant $(\mathrm{P}>0.05$

Conclusions: The remarkable finding in this study is that half of patients with AxSpA had a history of whiplash injury. These results suggest that trauma may influence the course of AxSpA through the immunological system or hypothalamic-pituitary-adrenal axis.

Disclosure of Interest: None declared

DOI: 10.1136/annrheumdis-2017-eular.3953

\section{SAT0401 PREVALENCE OF ULTRASONOGRAPHIC LOWER AND UPPER ENTHESITIS IN PATIENTS WITH INFLAMMATORY BOWEL DISEASE}

G. Cuomo ${ }^{1}$, M. Zappia ${ }^{2}$, M. Verde ${ }^{1}$, D. Sgambato ${ }^{2}$, M. Romano ${ }^{2} .{ }^{1}$ Dipartimento Assistenziale Integrato di Medicina Interna, UOC Medicina Interna - Università degli Studi della Campania - Luigi Vanvitelli; ${ }^{2}$ Dipartimento di internistica Clinica e Sperimentale, Università degli studi della Campania - Luigi vanvitelli, Napoli, Italy

Background: Spondyloarthritis (SpA) occurs in up to $20 \%$ of patients with inflammatory bowel disease (IBD) [1]. Symptomatic enthesitis is a characteristic feature of $\mathrm{SpA}$ and represents an early sign of $\mathrm{SpA}$ [2]. The prevalence of enthesitis in patients with IBD is not known.

Objectives: This study was designed to evaluate whether patients with IBD showed an increased prevalence of entheseal involvement, even in the absence of clinical symptoms.

Methods: Thirty-five IBD patients ( $25 \mathrm{M}$ and $10 \mathrm{~F}$, median age $41 \mathrm{yrs}$ ), 25 with Crohn's disease (CD) and 10 with ulcerative colitis (UC), all with moderate intestinal activity, and 22 (13 M and $12 \mathrm{~F}$, median age $44 \mathrm{yrs}$ ) control subjects with irritable bowel syndrome underwent a thorough clinical evaluation followed by entheses ultrasonography of upper limb (brachial triceps) and lower limb (quadriceps, proximal and distal rotuleus, Achilles tendon and plantar fascia). The Madrid sonographic entheses index (MASEI) was used to score entheses abnormalities [thickness, enthesophytosis, bursitis, erosions with and without power doppler (PD)]. Correlation between IBD features (type, duration and 